Article

\title{
Improvement of Thrust Bearing Calculation Considering the Convectional Heating within the Space between the Pads
}

\author{
Monika Chmielowiec-Jablczyk ${ }^{1}$, Andreas Schubert ${ }^{1, *}$, Christian Kraft ${ }^{2}$, Hubert Schwarze ${ }^{2}$, \\ Michal Wodtke ${ }^{3}$ and Michal Wasilczuk ${ }^{3}$ (D) \\ 1 GE Renewable Energy Hydro (Switzerland), Zentralstrasse 40, 5242 Birr, Switzerland; \\ monika.chmielowiec-jablczyk@ge.com \\ 2 Institute of Tribology and Energy Conversion Machinery, TU Clausthal, Leibnizstrasse 32, 38678 \\ Clausthal-Zellerfeld, Germany; kraft@itr.tu-clausthal.de (C.K.); schwarze@itr.tu-clausthal.de (H.S.) \\ 3 Faculty of Mechanical Engineering, Gdansk University of Technology, Narutowicza 11/12, 80-233 Gdansk, \\ Poland; mwodtke@pg.gda.pl (M.W.); mwasilcz@pg.gda.pl (M.W.) \\ * Correspondence: andreas.schubert1@ge.com; Tel.: +41-58-506-50-67
}

Received: 14 August 2017; Accepted: 10 February 2018; Published: 26 February 2018

\begin{abstract}
A modern thrust bearing tool is used to estimate the behavior of tilting pad thrust bearings not only in the oil film between pad and rotating collar, but also in the space between the pads. The oil flow in the space significantly influences the oil film inlet temperature and the heating of pad and collar. For that reason, it is necessary to define an oil mixing model for the space between the pads. In the bearing tool, the solutions of the Reynolds equation including a cavitation model, the energy equation and the heat transfer equation are done iteratively with the finite volume method by considering a constant flow rate. Both effects-laminar/turbulent flow and centrifugal force-are considered. The calculation results are compared with measurements done for a flooded thrust bearing with nominal eight tilting pads with an outer diameter of $180 \mathrm{~mm}$. The heat convection coefficients for the pad surfaces mainly influence the pad temperature field and are adjusted to the measurement results. In the following paper, the calculation results for variable space distances, influence of different parameters on the bearing behavior and operating condition at high load are presented.
\end{abstract}

Keywords: hydrodynamic bearing; thrust bearing calculation; thrust bearing test rig; thrust tilting pad

\section{Introduction}

The thrust bearing tool used in GE Renewable Energy Hydro for vertically-aligned hydro machines considered the distance between the pads in a range near $20 \%$ of the pad length. GE Renewable Energy Hydro started an investigation to study the distance influence for a higher range. Measurements on a test rig at Gdansk University of Technology were done for a flooded tilting pad thrust bearing. For the recalculation of the measurement, the tool Combros-A, developed at Clausthal University of Technology [1], was used. Finally, the influences of selected parameters, such as the distance between the pads, support system, speed, load, oil flow and the operating condition at high load were investigated. Loads higher than load during stationary operating conditions could occur for transient conditions such as a shut-down of a machine. The quasi-stationary solution is used.

The oil flow in the space has a major influence on the oil film inlet temperature $T_{A}$ and the heating of pad and collar. To estimate the oil film inlet temperature $T_{A}$ [2,3], the hot oil carry-over coefficient is used, which is the ratio inlet temperature rise $\left(T_{A}-T_{0}\right)$ to collar temperature rise $\left(T_{C}-T_{0}\right)$. The temperature $T_{0}$ is the oil supply temperature: the bearing housing temperature in a flooded 
bearing. The coefficient depends on the ratio oil film inlet gap to oil film outlet gap, varies between 0.6 and 0.9 and is based on experiments for several thrust bearing types. The temperatures $T_{A}$ and $T_{C}$ are constant average values and only a small variation of the distance between the pads is investigated. Further investigations of $[4,5]$ are based on experiments wherein the distance between the pads was changed by removing pads or decreasing the pad number, for example from eight to four. For the calculation, the oil film temperature is a constant average value. The difference between the oil film outlet and inlet temperature, $T_{E}$ and $T_{A}$, is estimated by power loss and flow. For the estimation of the average collar temperature $T_{C}$, the Peclet number, which is the ratio of the convective to conductive heat transport, is used. The bearing tool [6] uses the warm oil mixing factor in the range between 0 and 1 to describe the heat transport of the oil film outlet flow to oil film inlet of the following pad. The oil film temperature is a 3D field whereas the warm oil mixing factor depends on thrust bearing type and is an input value in the bearing tool. The influence of the oil supply on the oil mixing in the space between the pads is studied for a radial bearing in [7]. The three basic equations, Reynolds, energy and heating equations, are simultaneously solved. Numerical analysis of thermo-elastic hydrodynamic thrust bearings by using computational fluid dynamics (CFD) was done by $[8,9]$. In this paper, a modern thrust bearing tool is described which estimates the heating of the oil in the space between the pads using the energy and heating equation.

\section{Thrust Bearing Calculation Tool with the Oil Mixing Model}

The tool Combros-A is a TEHD (thermo-elastic hydrodynamic) bearing calculation software $[1,10]$ in which the Reynolds, energy and heating equations are solved iteratively. The oil film gap and pressure are 2D fields $(\varphi, r)$. The load capacity is primary defined by the minimum oil film gap. The heating of oil, pad and runner is estimated. Among wide range of physical effects considered in the calculation, a few key features should be mentioned: 3D fields $(\varphi, r, z)$ for velocity, temperature, viscosity and density including the effect of the centrifugal force, approximation of thermal and mechanical pad and collar deformation, local laminar and turbulent flow transition, cavitation model in divergent gap zones based on [11].

The model of the oil mixing in the space between the tilting pads is shown in Figure 1. The basic theory of the mixing model was published by [12]. For the replacement of the oil film outlet flow at trailing edge $Q_{E}$ by fresh oil with the temperature $T_{0}$, the oil replacing factor $f_{r}$ is used. $Q_{T}$ is the oil flow with the fresh oil temperature $T_{0}$ and $Q_{A}$ is the oil film inlet flow at leading edge with the oil film inlet temperature $T_{A}$.

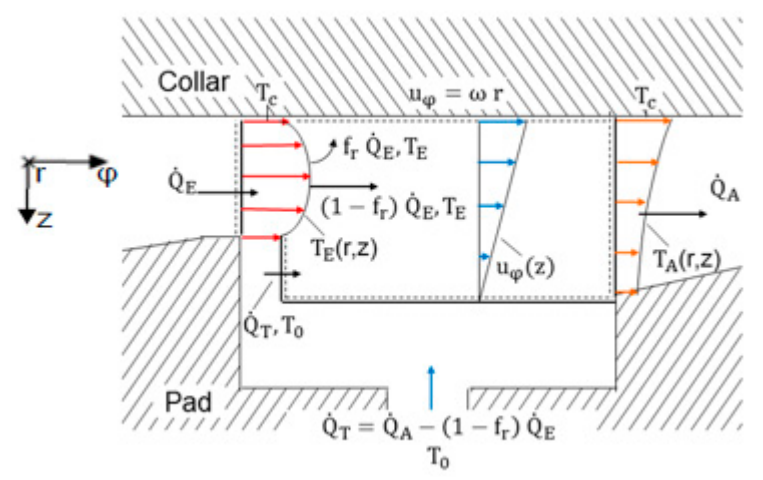

Figure 1. Model of the oil mixing in the space between the pads.

The flows at oil inlet and outlet $Q_{A}$ and $Q_{E}$ are 2D fields $(r, z)$. The hydraulic integrated oil flow balance is calculated as

$$
\left(1-f_{r}\right) Q_{E}+Q_{T}=Q_{A}
$$


The oil temperatures at oil inlet and outlet $T_{A}$ and $T_{E}$ are 2D fields $(r, z)$ like the flow fields. The fresh oil replacing factor $f_{r}$ depends on the thrust bearing type. Heating of the oil in the space and the resulting $3 \mathrm{D}$ oil temperature field $(\varphi, r, z)$ are estimated.

\section{Bearing Test Rig for Measurement}

Experimental investigations with different spaces between the pads (number of pads) and two support positions (removable ribs) at different speeds and loads were done on the bearing test rig [13]. A cross section of the bearing test rig is shown in Figure 2. The inlet of the rated oil flow $Q_{i n}$ is arranged on both bearing sides and there is one pipe for oil outlet flow $Q_{\text {out }}$ above the bearing housing. The configuration of pads and support systems are presented in Figure 3. The most important geometrical and operating data are summarized in Table 1.

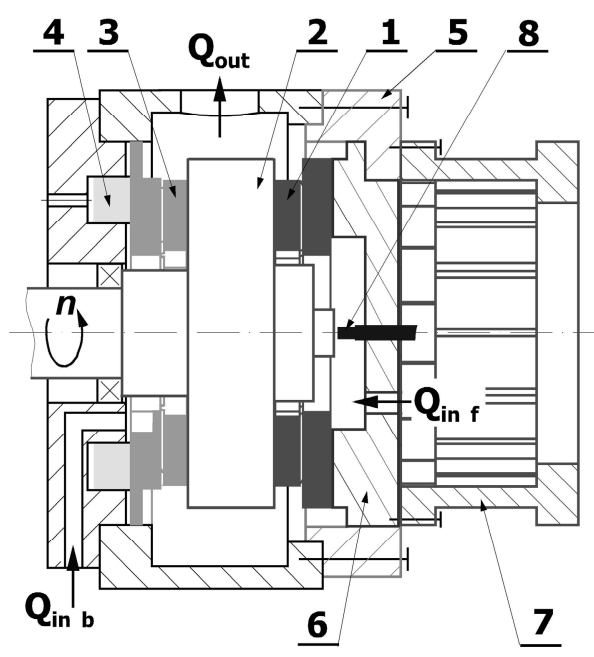

Figure 2. Cross section of the bearing test rig: 1-front thrust bearing, 2-runner, 3-rear thrust bearing, 4-loading system, 5-bearing housing, 6-plate, 7-torque sensor, 8-proximity probe.

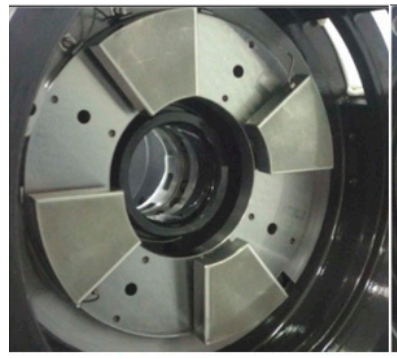

(a)

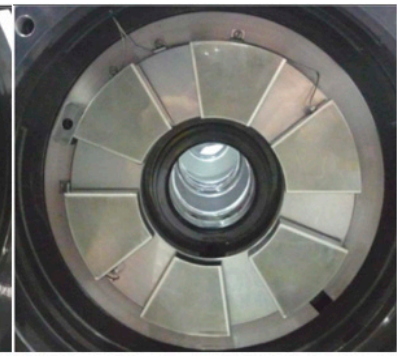

(b)

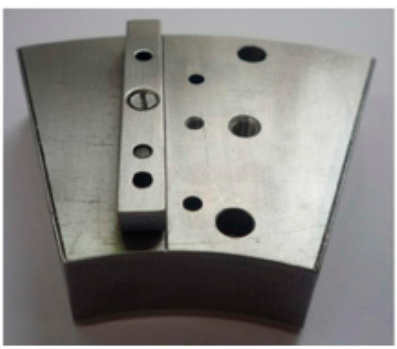

(e)

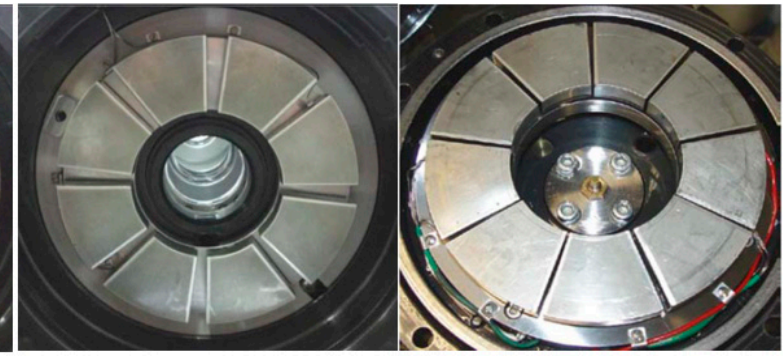

(c)

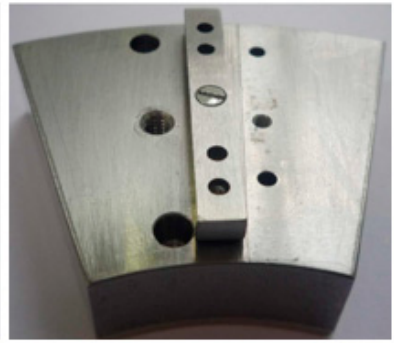

(f)

Figure 3. Arrangement of pads at test rig, $N_{\text {pad }}=4 / 6 / 8 / 9$ pads (a-d), supporting rib: offset support (e), central support (f) [14]. 
Table 1. Geometry and operating data [14].

\begin{tabular}{cc}
\hline Parameter & Value \\
\hline Outer $/$ mean $/$ inner diameter & $180 / 135 / 90 \mathrm{~mm}$ \\
Pad angle, $\alpha_{\text {pad }}$ & $38^{\circ}$ \\
Number of pads, $N_{\text {pad }}$ & $4 / 6 / 8 / 9$ \\
Angular pivot position & 0.6 (offset) $/ 0.5$ (central) \\
Body pad-/Total pad thickness & $14 / 18.2 \mathrm{~mm}$ \\
Collar thickness & $50 \mathrm{~mm}$ \\
Specific pressure & $2 / 3 \mathrm{MPa}$ \\
Rotational speed & $2000 / 3000 / 4000 \mathrm{rpm}$ \\
Oil grade & ISO VG 32 \\
Oil inlet temperature & $40^{\circ} \mathrm{C}$ \\
Oil flow rate, $Q_{\text {in }}$ & $15.1 / 22.0 \mathrm{~L} / \mathrm{min}$ \\
\hline
\end{tabular}

The pads were equipped with twelve temperature sensors. Nine of them were installed in the pad, seven (red dots) in the holes drilled through the whole pad thickness to monitor temperature next to hydrodynamic oil film gap on the pad surface and two others (blue dots) about $3 \mathrm{~mm}$ from the pad bottom. Another three sensors (green dots) were located in the collar near the inner and outer radius and in the middle of thrust bearing about $2 \mathrm{~mm}$ below the collar surface. The arrangement of temperature sensors for pad and collar is shown in Figure 4.
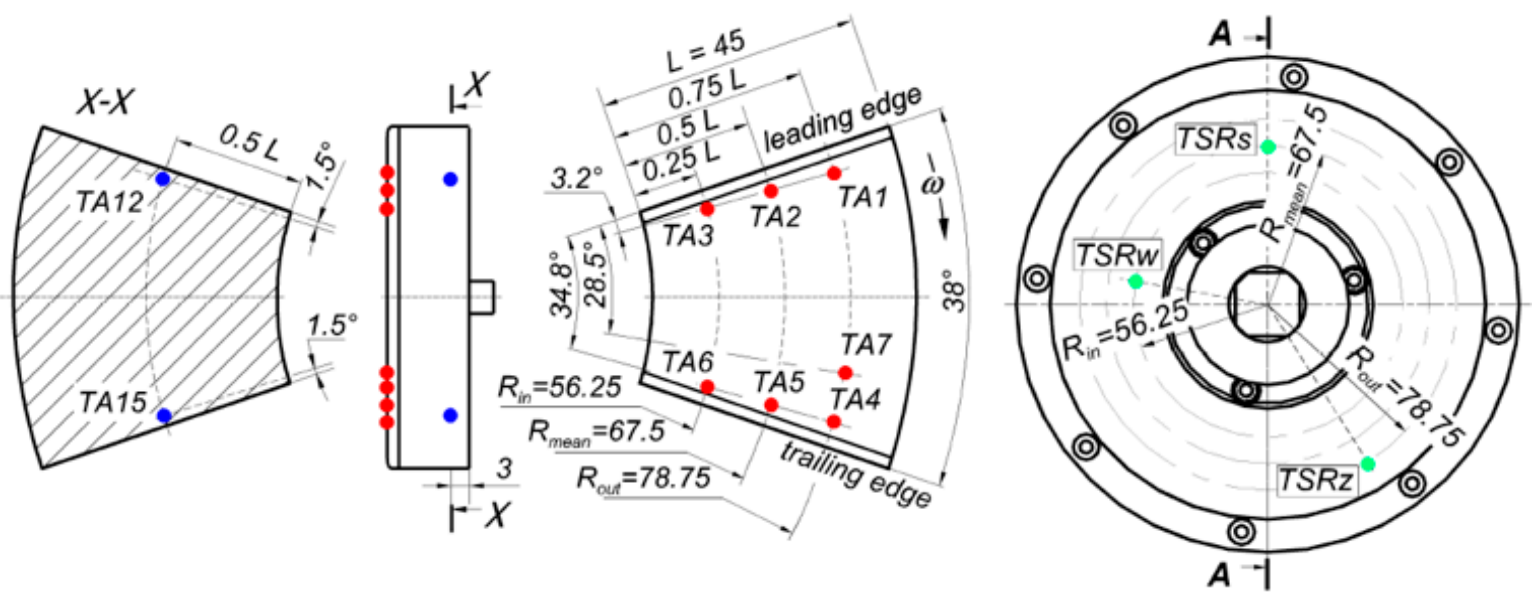

Figure 4. Arrangement of pad and collar temperature sensors, pad (left), collar (right), [14].

Based on increase of the oil temperature in the bearing housing $\Delta T=T_{\text {out }}-T_{\text {in }}$ and oil flow rate $Q_{i n}$, the total power loss $P_{\text {bear }}$ is determined. Constant values for oil density $\rho=867 \mathrm{~kg} / \mathrm{m}^{3}$ and oil specific heat $c_{p}=2112.5 \mathrm{~J} / \mathrm{kg} \cdot \mathrm{K}$ were assumed. The conductive power loss over the bearing housing to the environment is neglected.

\section{Recalculation of the Measurement}

\subsection{Combros-A Calculation}

The thrust bearing is fully flooded with oil, the angular pad pivot positions are 0.6 (offset) and 0.5 (central) and the pad number varies between four and nine. The variables in Table 2 are estimated with measurement results at speed $4000 \mathrm{rpm}$ and a specific pressure of $3 \mathrm{MPa}$. The pad surface overlapping factor $f_{\text {surf }}$ is the ratio pad area to ring area. As shown in the following Section 5 , the fresh oil replacing factor corresponds to the bearing type and not to operating data such as speed and specific pressure. 
Table 2. Fresh oil replacing factor.

\begin{tabular}{ccccccc}
\hline $\boldsymbol{N}_{\text {pad }}$ & $f_{\text {surf }}$ & Pivot & $\boldsymbol{T}_{\text {in }}\left({ }^{\circ} \mathbf{C}\right)$ & $\boldsymbol{T}_{\text {out }}\left({ }^{\circ} \mathbf{C}\right)$ & $\boldsymbol{T}_{\boldsymbol{0}}\left({ }^{\circ} \mathbf{C}\right)$ & $f_{\boldsymbol{r}}$ \\
\hline 4 & 0.422 & offset & 40.0 & 53.8 & 46.9 & 0.600 \\
6 & 0.633 & offset & 40.0 & 55.8 & 47.9 & 0.520 \\
8 & 0.844 & offset & 40.0 & 57.4 & 48.7 & 0.440 \\
9 & 0.950 & offset & 40.3 & 59.2 & 49.8 & 0.400 \\
4 & 0.422 & central & 40.0 & 54.4 & 47.2 & 0.800 \\
6 & 0.633 & central & 40.0 & 56.4 & 48.2 & 0.720 \\
8 & 0.844 & central & 40.0 & 58.1 & 49.1 & 0.640 \\
9 & 0.950 & central & 40.5 & 59.5 & 50.0 & 0.600 \\
\hline
\end{tabular}

In [8], the effect of the heat convection coefficient at the pad surfaces of a tilting pad thrust bearing is studied by using CFD investigations. The tool Combros-A defines average heat transfer coefficients at the five surfaces at the leading edge, trailing edge, outer radius, inner radius and bottom. The pad heat convection coefficients from Table 3 are estimated by comparison of measurement at speed of $4000 \mathrm{rpm}$ and specific pressure of $3 \mathrm{MPa}$. The value of the heat convection coefficient on the bottom side is high and the physical background was not finally clarified. Only with this high value do the calculated pad temperatures near pad bottom agree with the measurements. The surrounding surface temperatures depend on the temperatures in the bearing housing and therefore from the heating of the oil in the housing caused by bearing power loss. The change of the heat convection coefficients at different speeds seems to be low as shown in the following Section 6. The values from Table 3 are used in this paper for all operating conditions investigated.

Table 3. Heat convection coefficient at the pad surfaces for calculation.

\begin{tabular}{|c|c|}
\hline Surface Side & Heat Convection Coefficient $\left(\mathrm{W} / \mathrm{m}^{2} / \mathrm{K}\right)$ \\
\hline Leading & 350 \\
\hline Trailing & 175 \\
\hline Outer radius & 175 \\
\hline Inner radius & 175 \\
\hline Bottom & 3500 \\
\hline
\end{tabular}

The pads are arranged on the both sides of the collar, Figure 2. The symmetrical collar temperature curve from the middle of the collar to both pads allows the collar to divide in two parts and no heat transfer to be estimated at the middle surface. The heat transfers near the outer and inner collar diameter are low because of their small surfaces in comparison to the middle collar surface. The values used in the calculation tool are shown in Table 4; the surrounding surface temperatures are adapted to the temperatures in the bearing housing.

Table 4. Heat convection coefficient at the collar surfaces for calculation.

\begin{tabular}{|c|c|}
\hline Surface Side & Heat Convection Coefficient $\left(\mathrm{W} / \mathrm{m}^{2} / \mathrm{K}\right)$ \\
\hline Middle & 10 \\
\hline Outer radius & 1000 \\
\hline Inner radius & 1000 \\
\hline
\end{tabular}

The heating of the oil in the film, the oil in the space between the pads, the pad and collar are shown in Figure 5 for 8 and 4 pads at rotational speed of $4000 \mathrm{rpm}$ and specific pressure of $3 \mathrm{MPa}$. The graphical outputs show the temperature fields at the mean diameter $D_{\text {mean }}=135 \mathrm{~mm}$. More pads are creating higher dissipation in the oil film and therefore higher heating of space, pad and collar. Calculated power losses in oil film, the space and the heat flow to pad and collar are summarized in Table 5. The percentage value in the parentheses is the ratio heat to sum of both calculated power losses, $P_{f, p a d}+P_{f, \text { space }}$. 

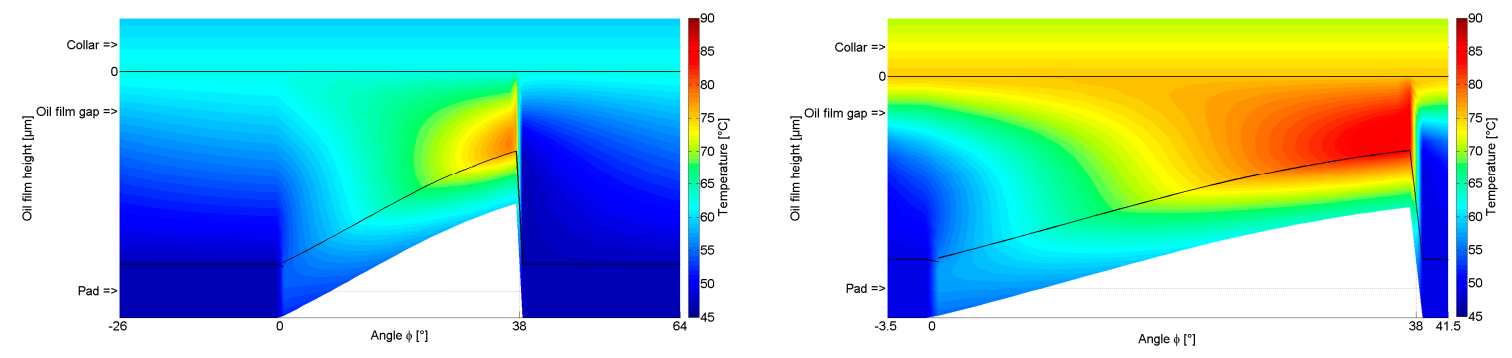

Figure 5. Calculated temperature field at the mean diameter, offset pivot. $N_{\text {pad }}=4$ (left)/8 (right), rotational speed $4000 \mathrm{rpm}$, specific pressure $3 \mathrm{MPa}, T_{0,4 \text { pads }}=46.9^{\circ} \mathrm{C}, T_{0,8 p a d s}=48.7^{\circ} \mathrm{C}$.

Table 5. Calculated power losses and heat flows: rotational speed $4000 \mathrm{rpm}$, specific pressure $3 \mathrm{MPa}$.

\begin{tabular}{ccc}
\hline Power & 4 Pads Offset & 8 Pads Offset \\
\hline$P_{\text {f,pad }}(\mathrm{kW})$ & 2.881 & 5.209 \\
$P_{f, \text { space }}(\mathrm{kW})$ & 0.628 & 0.328 \\
Heat flow into pads $(\mathrm{kW})$ & $0.287(8.2 \%)$ & $0.698(12.6 \%)$ \\
Heat flow into collar $(\mathrm{kW})$ & $0.194(5.5 \%)$ & $0.363(6.6 \%)$ \\
\hline
\end{tabular}

\subsection{Comparison with Collar and Pad Temperature Measurement}

Figures 6 and 7 show a comparison of measured and calculated temperatures for collar and pad. The radii of the collar, where the temperature was measured, are shown in Figure 4 (right). For the pad, three temperatures at $r=78.75 \mathrm{~mm}$ in the circumferential direction were chosen. The results show good agreement between the measured and predicted values, especially in case of the eight pads with higher temperatures. The higher collar and pad heating for more pads could be observed. The pad temperature TA1 near the oil film inlet (small angle $\alpha$ ), Figure 7, is lower for a reduced number of pads. Lower pad temperature TA1 relates to lower oil film inlet temperature $T_{\text {in }}$ which is estimated by using the fresh oil replacing factor $f_{r}$.
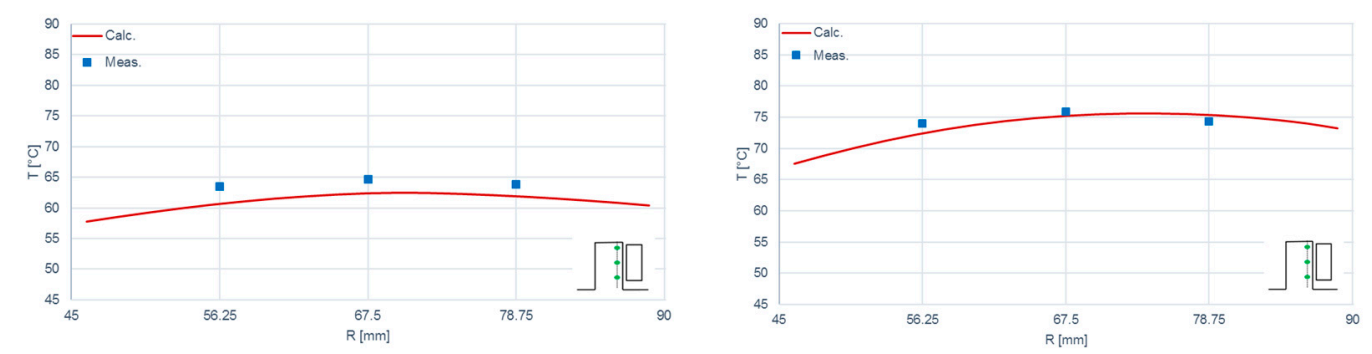

Figure 6. Comparison of calculated and measured collar temperatures, offset pivot. Sensors: TSR $w$ TSRs, TSRz, $N_{\text {pad }}=4$ (left) $/ 8$ (right), rotational speed $4000 \mathrm{rpm}$, specific pressure $3 \mathrm{MPa}$.
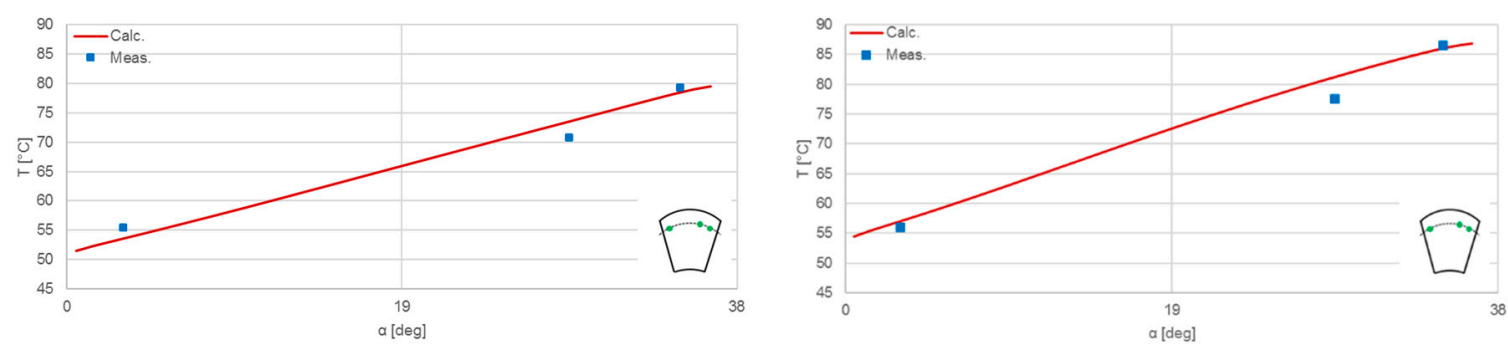

Figure 7. Comparison of calculated and measured pad temperatures, offset pivot. Sensors: TA1, TA7, TA4, $N_{\text {pad }}=4$ (left) $/ 8$ (right), rotational speed $4000 \mathrm{rpm}$, specific pressure $3 \mathrm{MPa}$. 


\subsection{Bearing Power Loss}

Measured bearing power loss $P_{\text {bear }}$ estimated with the oil temperature difference in the bearing housing $\Delta T=T_{\text {out }}-T_{\text {in }}$ and oil flow rate $Q_{\text {in }}$ is higher than the calculated sum of the power loss in the oil film gap and the space between the pads. The free collar rotational surfaces outside the range of outer and inner pad diameter, Figure 2, create additional rotating power loss $P_{f, r o t}$. The bearing tool does not consider free rotating surfaces, therefore in Table 6 the rotational power loss, $P_{f, r o t}$, is calculated by subtraction of the measured and calculated power losses:

$$
P_{f, \text { rot }}=P_{\text {bear }}-P_{f, p a d}-P_{f, \text { space }}
$$

GE Renewable Energy Hydro calculates similar values for rotational power loss, $P_{f, r o t}$ by using an experienced formula.

Table 6. Rotational power loss $P_{f, \text { rot }}$ rotational speed $4000 \mathrm{rpm}$, specific pressure $3 \mathrm{MPa}$.

\begin{tabular}{ccc}
\hline Power & 4 Pads Offset & 8 Pads Offset \\
\hline$P_{\text {bear }}(\mathrm{kW})$ & 6.37 & 8.03 \\
$P_{\text {f,pad }}(\mathrm{kW})$ & 2.881 & 5.209 \\
$P_{f, \text { space }}(\mathrm{kW})$ & 0.628 & 0.328 \\
$P_{f, \text { rot }}(\mathrm{kW})$ & 2.861 & 2.493 \\
\hline
\end{tabular}

\section{Collar and Pad Heating Depending on Distance between the Pads}

The influence of the collar and pad temperatures on the distance between the pads $l_{\text {distance }}$ is shown in Figure 8 for offset pivot and in Figure 9 for central pivot. The $x$-axis represents the surface factor $f_{\text {surf }}$, the dimensionless ratio $l_{\text {pad }}$ to $l_{\text {arc }}$ with the pad length $l_{\text {pad }}=D_{\text {mean }} \pi \alpha_{\text {pad }} / 360^{\circ}$ and the arc length $l_{\text {arc }}=D_{\text {mean }} \pi / N_{\text {pad }}$. The distance between the pads $l_{\text {distance }}=l_{\text {arc }}-l_{\text {pad }}$.

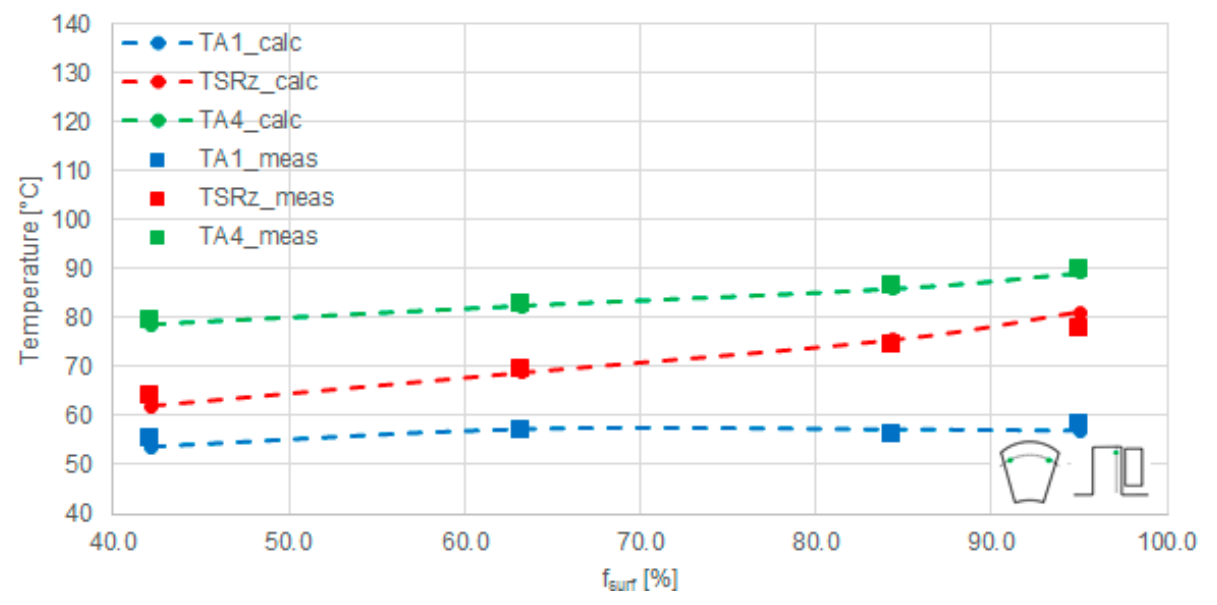

Figure 8. Calculated and measured temperatures as a function of surface factor, offset pivot. Sensors: TA1, TSRz, TA4, $N_{\text {pad }}=4 / 6 / 8 / 9$, rotational speed $4000 \mathrm{rpm}$, specific pressure $3 \mathrm{MPa}$. 


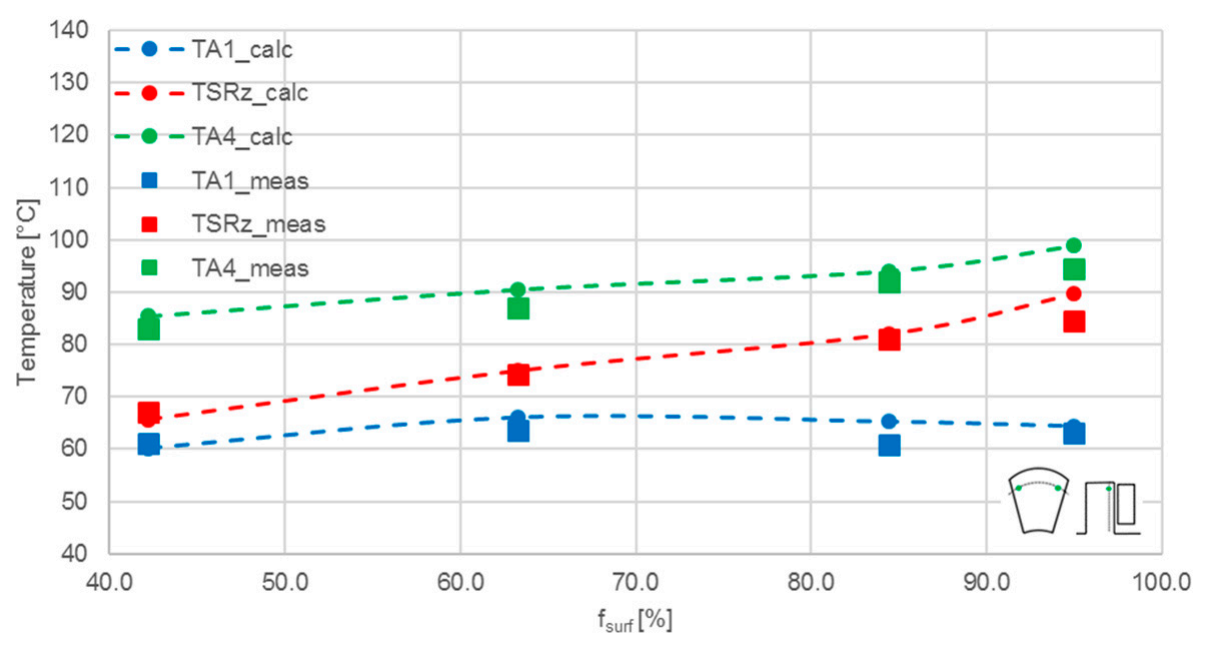

Figure 9. Calculated and measured temperatures as a function of surface factor, central pivot. Sensors: TA1, TSRz, TA4, $N_{\text {pad }}=4 / 6 / 8 / 9$, rotational speed $4000 \mathrm{rpm}$, specific pressure $3 \mathrm{MPa}$.

The heating of the collar is shown with the temperature at radius $r=78.75 \mathrm{~mm}$ (sensor TSRz). For the pad, two locations at the same radius were chosen near the leading and trailing edge at the angles $\alpha=3.2^{\circ}$ and $34.8^{\circ}$ (sensor TA1 and TA4). The single quadrats in the graphics represent the measured sensor temperatures.

There is an increase mainly of collar temperature TSRz for an increasing surface factor $f_{\text {surf }}$. For small number of pads (low surface factor) the collar temperature TSRz is closer to the pad temperature at oil film inlet side TA1 and increases to pad temperature at oil film outlet side TA4 for higher number of pads, as shown in [4]. There are the same trends of the curves for offset and central pivot.

The three power loss components in oil film, space and on free collar rotational surfaces, $P_{f, p a d}$, $P_{f, s p a c e}, P_{f, r o t}$, are shown in Figure 10 for the offset pivot and in Figure 11 for the central pivot depending on the surface factor $f_{\text {surf }}$. The low values of the space power loss $P_{f, \text { space }}$ are significant. The measured bearing power loss $P_{\text {bear }}$ is not significantly different between offset and central pivot. The lower losses due to higher temperatures are compensated by the higher losses due to smaller oil film gaps.

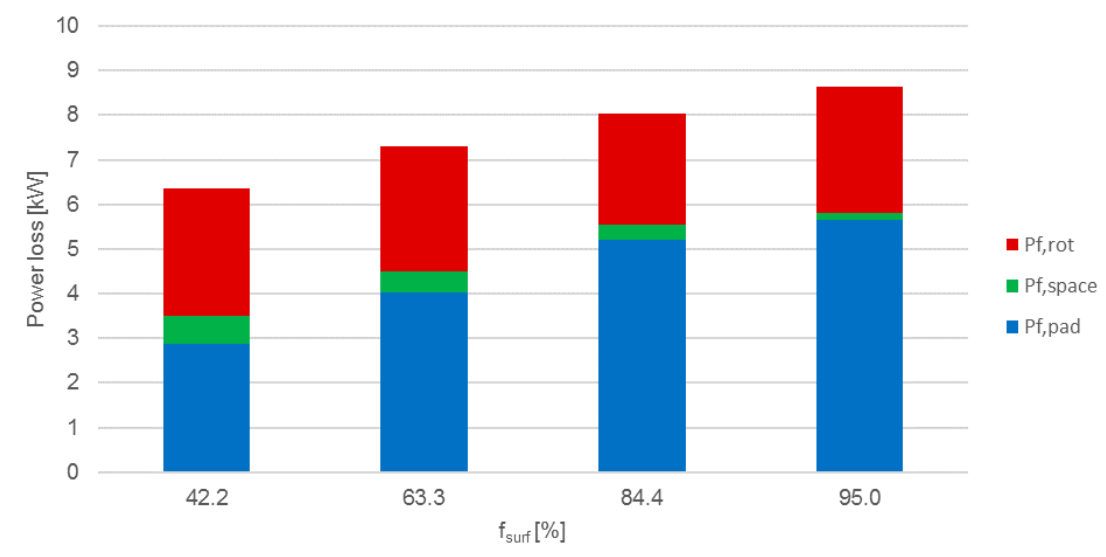

Figure 10. Power losses as a function of surface factor, offset pivot. $N_{\text {pad }}=4 / 6 / 8 / 9$, rotational speed $4000 \mathrm{rpm}$, specific pressure $3 \mathrm{MPa}$. 


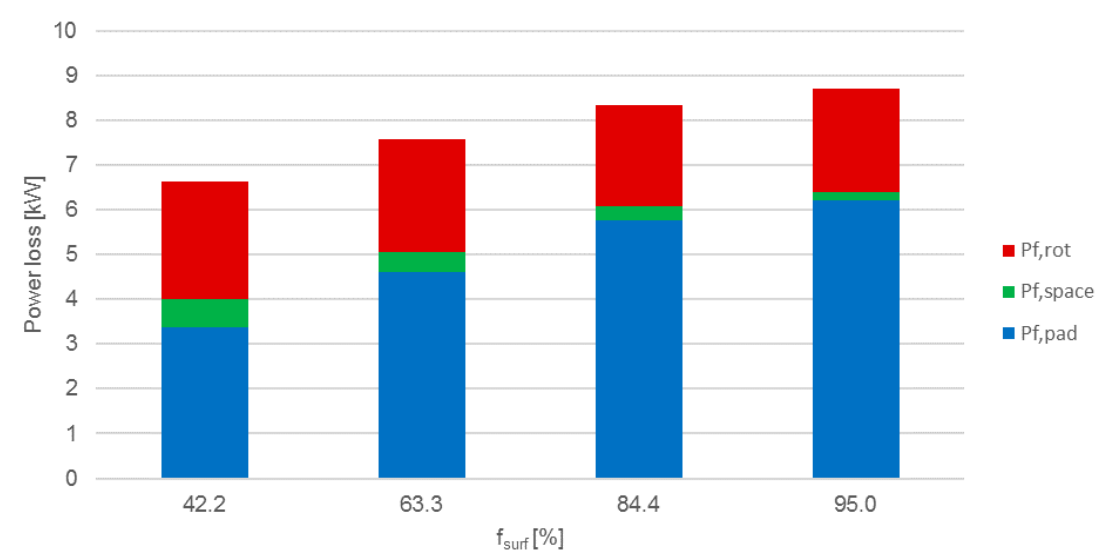

Figure 11. Power losses as a function of surface factor, central pivot. $N_{\text {pad }}=4 / 6 / 8 / 9$, rotational speed $4000 \mathrm{rpm}$, specific pressure $3 \mathrm{MPa}$.

\section{Sensitivity Analysis}

In the following chapter, the influence of different parameters, such as pad pivot position, rotational speed, thrust load, oil flow rate, on the bearing behavior and the operating condition of a high load is presented.

\subsection{Pad Pivot Position}

For an eight-pad design at $4000 \mathrm{rpm}$ and $3 \mathrm{MPa}$, the influence on both support systems, offset and central pivot, was investigated. Oil film pressure curves are different, as shown in Figure 12, with the consequence that the pad tilting for the central pivot is lower than for offset pivot. Lower pad tilting creates higher temperatures in space, pad and collar, as shown in Figure 13. The oil film inlet and outlet gap as well as temperature fields are shown in Figure 14. The replacing factor is higher for the central pivot, as shown in Table 2, and seems to depend on the ratio inlet to outlet oil film gap. The dependence on this ratio was also found in [2] for the hot oil carry-over coefficient.
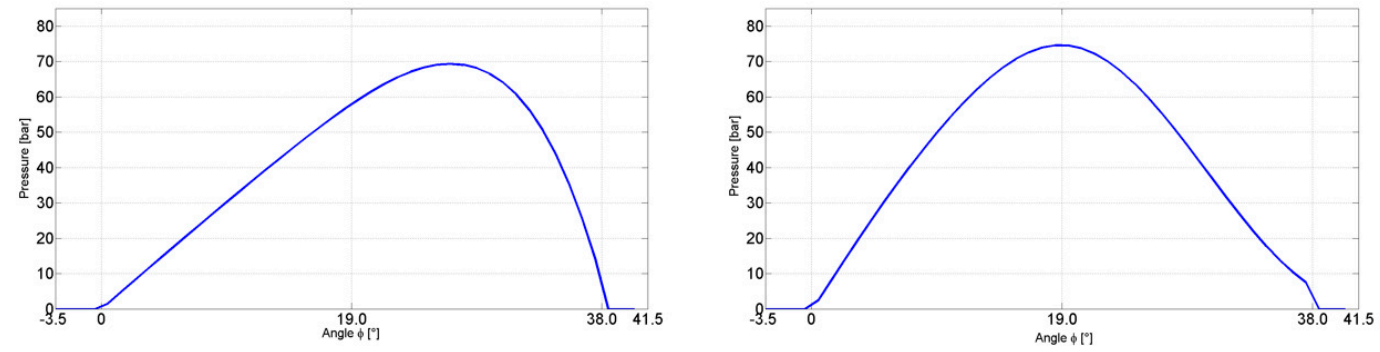

Figure 12. Calculated oil film pressure at mean radius, pivot: offset (left), central (right). $N_{\text {pad }}=8$, rotational speed $4000 \mathrm{rpm}$, specific pressure $3 \mathrm{MPa}$.
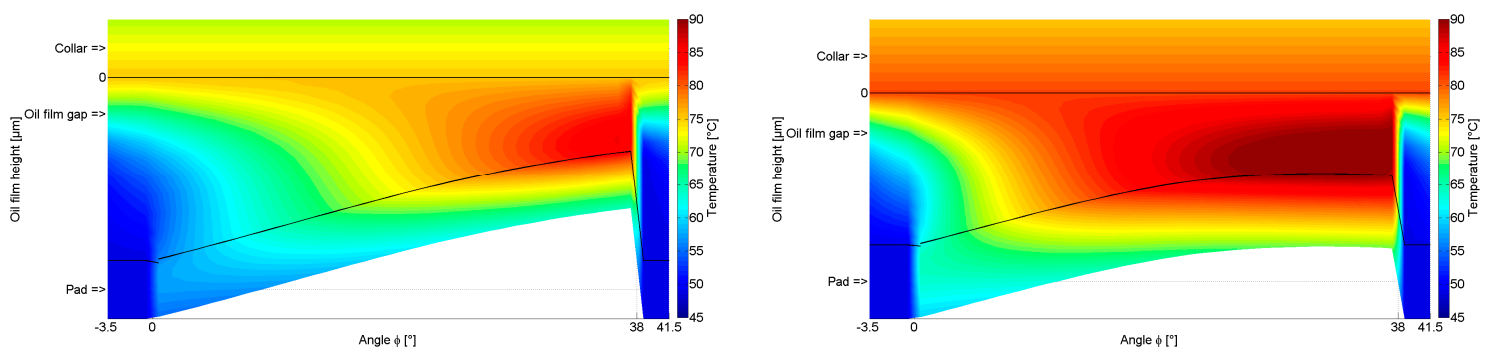

Figure 13. Calculated temperature fields at mean diameter, pivot: offset (left), central (right). $N_{\text {pad }}=8$, rotational speed $4000 \mathrm{rpm}$, specific pressure $3 \mathrm{MPa}, T_{0, \text { offset }}=48.7^{\circ} \mathrm{C}, T_{0, \text { central }}=49.1^{\circ} \mathrm{C}$. 


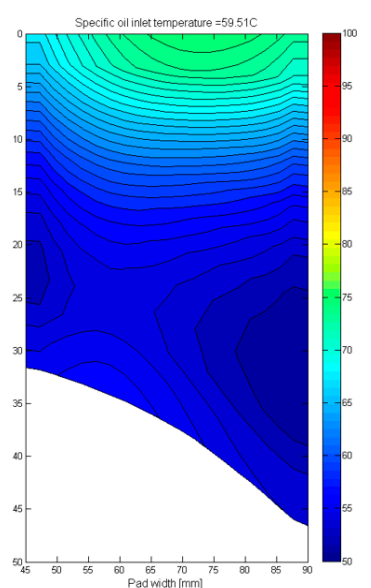

(a)

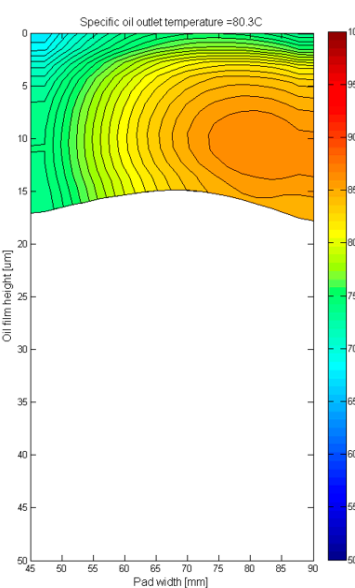

(b)

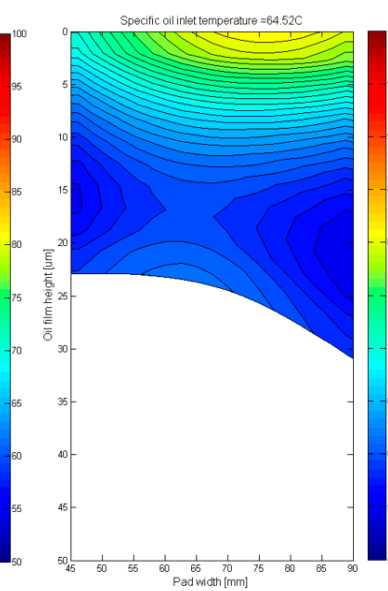

(c)

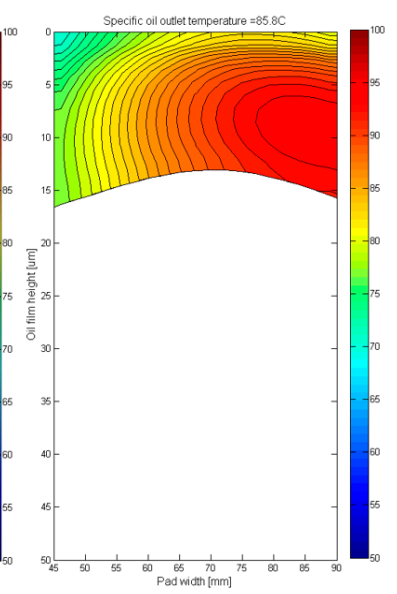

(d)

Figure 14. Calculated oil film inlet/outlet gap and temperature fields, pivot: offset (a/b), central (c/d).

\subsection{Rotational Speed}

The speed was reduced from 4000 to $2000 \mathrm{rpm}$ at a specific pressure of $3 \mathrm{MPa}$. Calculated and measured pad and collar temperatures are shown for offset pivot and all number of pads: see Figure 15.

All temperatures are lower in case of the reduced speed in good agreement with the measured data. The fresh oil replacing factor does not depend on operating condition.
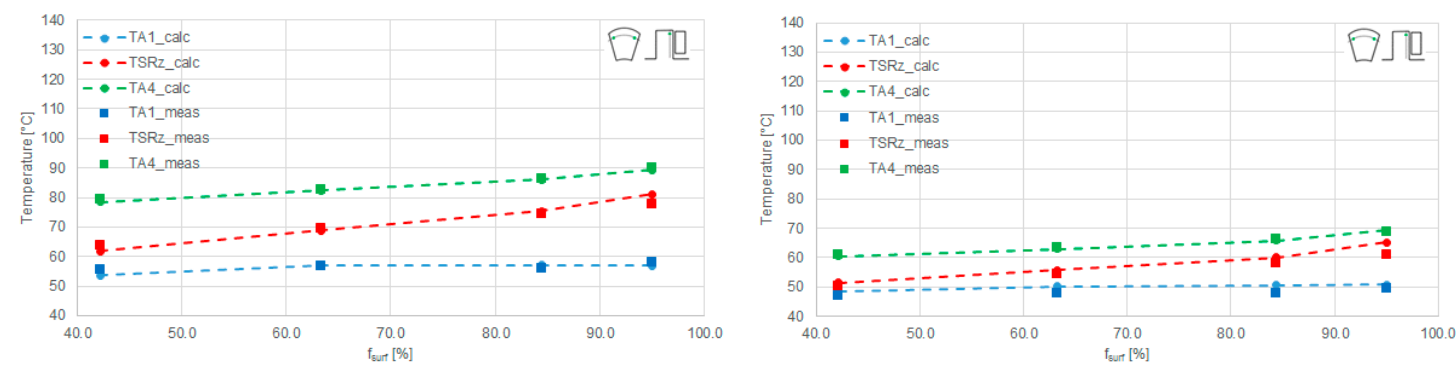

Figure 15. Calculated and measured temperatures as a function of surface factor, offset pivot. Sensors: TA1, TSRz, TA4, $N_{\text {pad }}=4 / 6 / 8 / 9$, rotational speed 4000 (left) $/ 2000$ (right) rpm, specific pressure $3 \mathrm{MPa}$.

\subsection{Thrust Load}

To analyze thrust load sensitivity, the specific pressure was reduced from 3 to $2 \mathrm{MPa}$ at a rotational speed of $4000 \mathrm{rpm}$. The calculated and measured pad and collar temperatures are shown for offset pivot and all investigated number of pads in Figure 16. All temperatures decrease with lower pressure in good agreement with measured data.
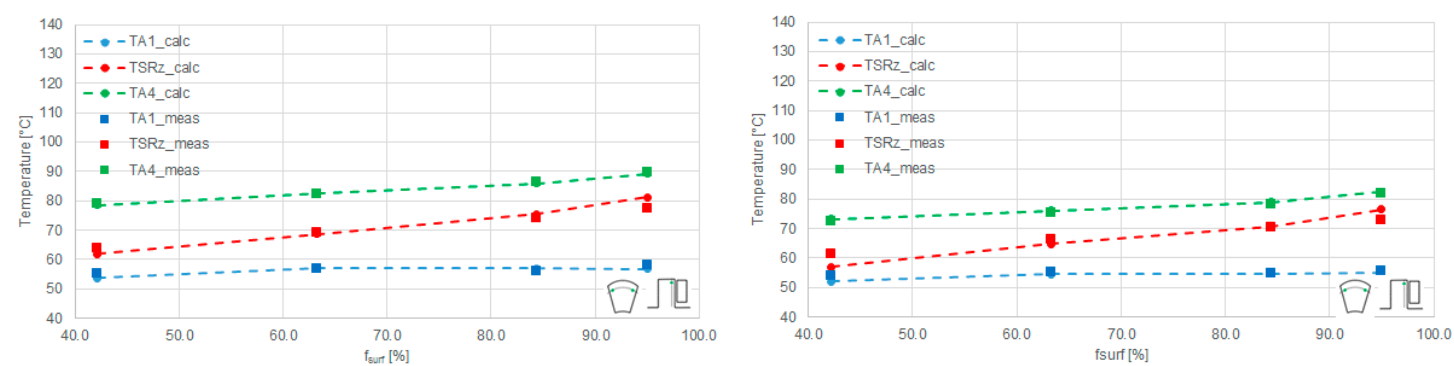

Figure 16. Calculated and measured temperatures as a function of surface factor, offset pivot. Sensors: TA1, TSRz, TA4, $N_{\text {pad }}=4 / 6 / 8 / 9$, rotational speed $4000 \mathrm{rpm}$, specific pressure 3 (left) $/ 2$ (right) MPa. 


\subsection{Oil Flow Rate}

To analyze the sensitivity of the oil flow rate at $4000 \mathrm{rpm}$ and $3 \mathrm{MPa}$ on the test rig, $Q_{\text {in }}$ was increased from 15.1 to $22.0 \mathrm{~L} / \mathrm{min}$. This causes a lower increase of the oil temperature in the bearing housing $\left(\Delta T=T_{\text {out }}-T_{\text {in }}\right)$. The calculated pad temperatures are approximately $3 \mathrm{~K}$ lower as shown in Figure 17.
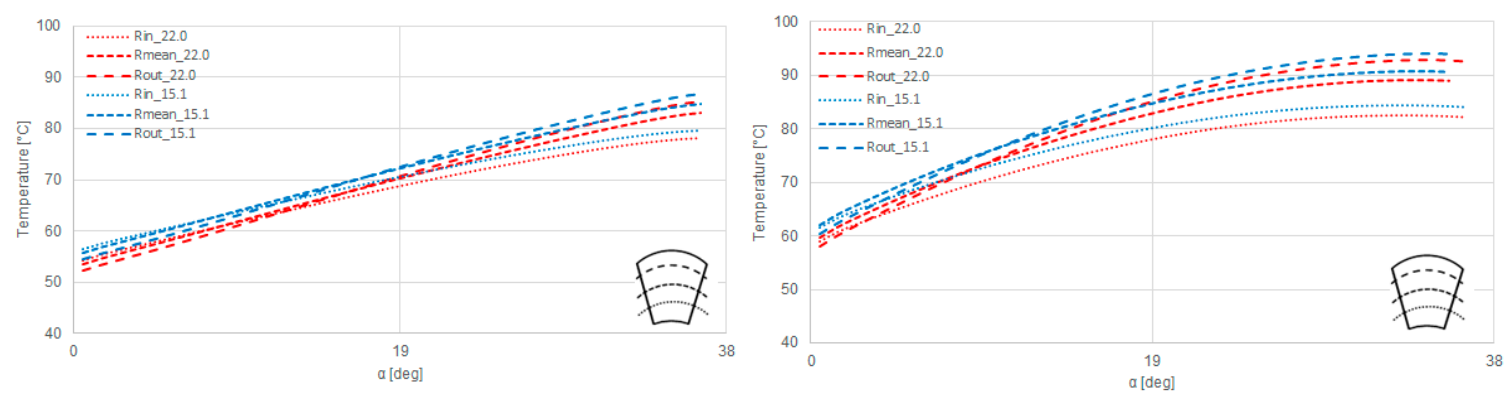

Figure 17. Influence of the oil flow on calculated pad temperatures, Offset pivot (left), central pivot (right). $N_{\text {pad }}=8$, rotational speed $4000 \mathrm{rpm}$, mean pressure $3 \mathrm{MPa}$.

\subsection{High Thrust Load}

High thrust load can occur for example during an emergency stop of a vertically-aligned hydro generator. For the eight-pad design with offset pivot, the thrust load was increased from 3 to $6 \mathrm{MPa}$ at rotational speed of $4000 \mathrm{rpm}$, as shown in Figure 18. As this load value is outside the measured range of the test rig, only calculation results are shown by using the fresh oil replacing factor which is independent from operating condition. There is a decrease of oil film thickness and an increase of the temperature for higher load.
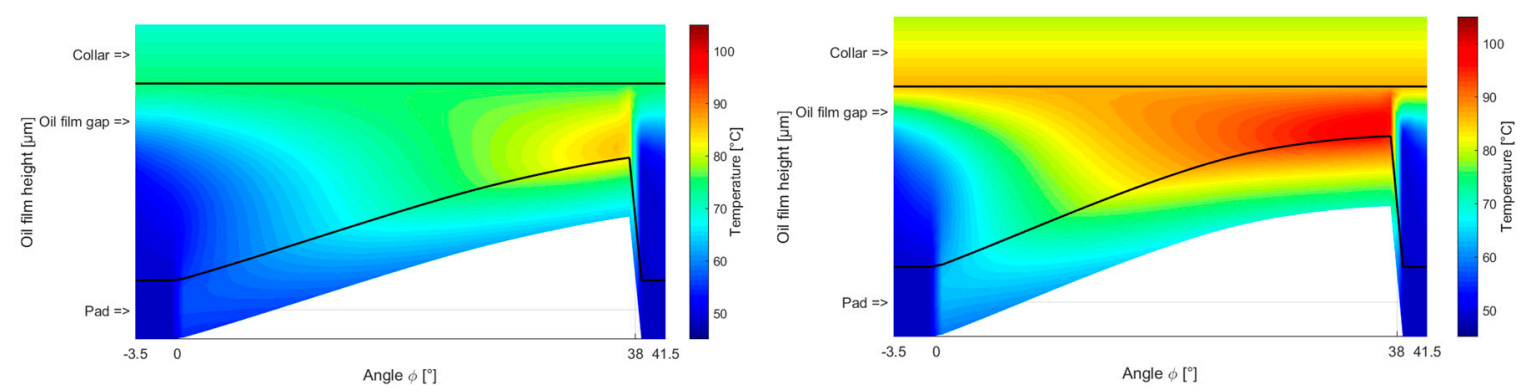

Figure 18. Calculated temperature fields at mean diameter, pivot: offset. $N_{\text {pad }}=8$, rotational speed $4000 \mathrm{rpm}$, specific pressure 3 (left)/6 MPa (right).

\section{Conclusions}

Recalculation of measurements was carried out for a fully flooded tilting pad thrust bearing by using Combros-A calculation tool, which solves the Reynolds, energy and heating equations iteratively. The variation of pad number in a thrust bearing leads to different distances between the pads. Its influence on the thermal behavior is the focus of this publication. The overlapping factor, a dimensionless value, is used to describe the pad distance. An oil mixing model for the space between the pads is defined, and the fresh oil replacing factor depends on the bearing types. The fresh oil replacing factor changes for different pad distances but is independent from operating conditions such as speed and load. A good agreement between calculation and measurements was reached by using the adjusted values shown in Table 2. 
Author Contributions: Michal Wodtke and Michal Wasilczuk designed the experiment and analyzed the experimental data; Hubert Schwarze and Christian Kraft developed the tool, Monika Chmielowiec-Jablczyk and Andreas Schubert analyzed the calculated data and wrote the paper.

Conflicts of Interest: The authors declare no conflict of interest.

\section{Nomenclature}

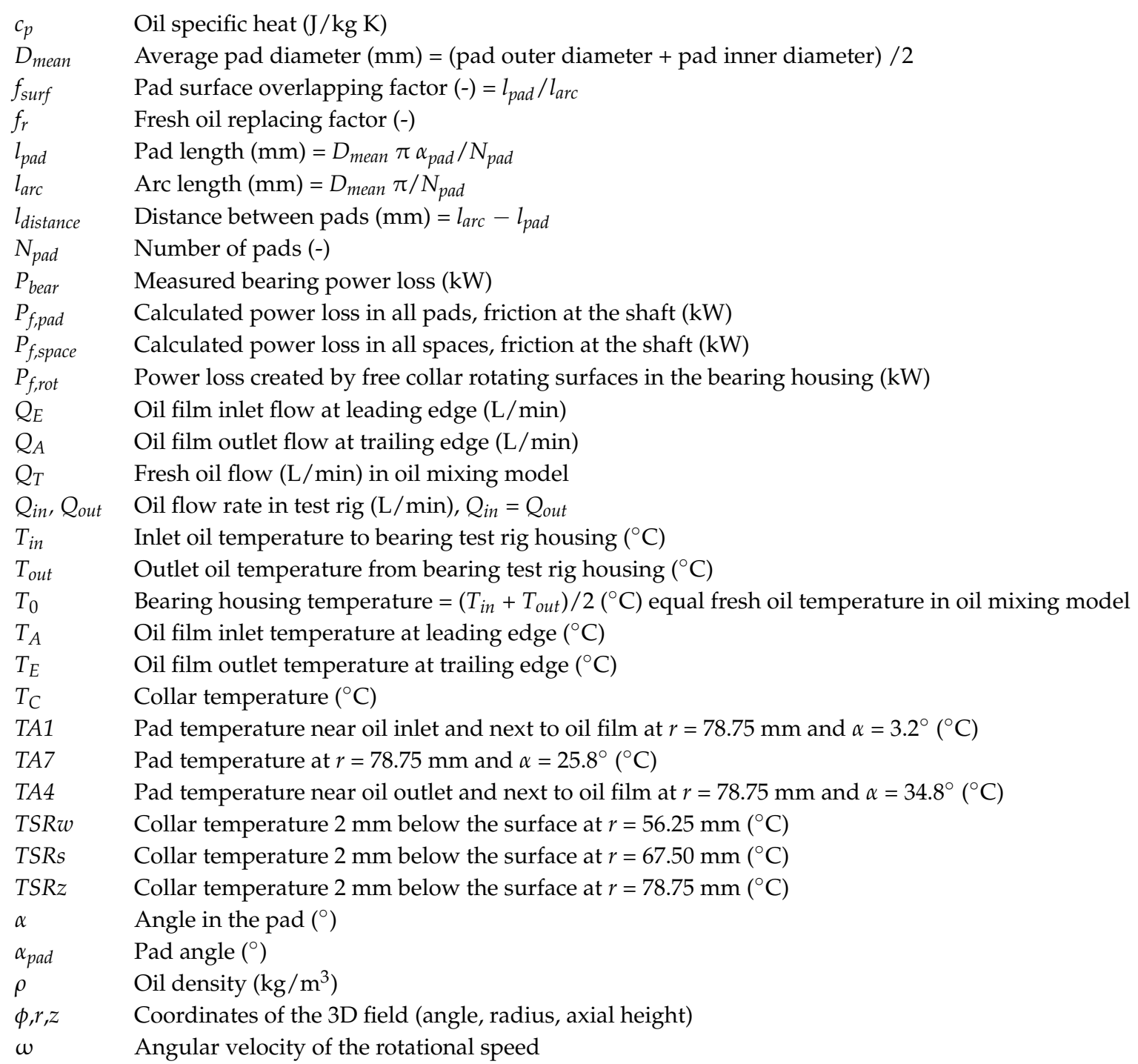

\section{References}

1. Kraft, C.; Schwarze, H. Verbesserte Axialgleitlagerberechnung; FVV Final Report; Heft 1019; FVV-Berichte: Frankfurt am Main, Germany, 2012.

2. Ettles, C. Hot Oil Carryover in Thrust Bearings; Part 3L; MCB Univ. Press Ltd.: Yorkshire, UK, 1970; Volume 184, pp. $75-81$.

3. Ettles, C.; Cameron, A. Considerations of Flow across a Bearing Groove. J. Lubr. Technol. 1968, 90, 312-319. [CrossRef]

4. Neal, P.B. Heat Transfer in Pad Thrust Bearings. Proc. Inst. Mech. Eng. 1982, 196, 217-228. [CrossRef]

5. Neal, P.B. Some Factors Influencing the Operating Temperature of Pad Thrust Bearings. In Proceedings of the 6th Leeds-Lyon Symposium, Lyon, France, 18-21 September 1979; pp. 137-142.

6. Fust, A. Dreidimensionale Thermohydrodynamische Berechnung von Axiallagern mit Punktförmig Abgestützte Segmenten. Ph.D. Thesis, ETH Zurich, Zürich, Switzerland, 1981. 
7. Hagemann, T. Ölzuführungseinfluss bei Schnell laufenden, hoch Belasteten Radialgleitlagern unter Berücksichtigung des Lagerdeformationsverhaltens. Ph.D. Thesis, TU Clausthal, Clausthal-Zellerfeld, Germany, 2012.

8. Wodtke, M.; Fillon, M.; Schubert, A.; Wasilczuk, M. Study of the Influence of Heat Convection Coefficient on Predicted Performance of a Large Tilting-Pad Thrust Bearing. ASME J. Tribol. 2013, 108, 231-248. [CrossRef]

9. Pajaczkowski, P. Simulation of Transient States in Large Hydrodynamic Thrust Bearing. Ph.D. Thesis, Gdansk University of Technology, Gdańsk, Poland, 2010.

10. Kraft, C.; Schwarze, H. Benutzeranleitung für das Axialgleitlagerberechnungsprogramm COMBROS-A, Version 1.4; TU Clausthal: Clausthal-Zellerfeld, Germany, 2017.

11. Elrod, H.G. A Cavitation Algorithm. ASME J. Lubr. Technol. 1981, 103, 350-354. [CrossRef]

12. Vohr, J.H. Discussion about "Mixing Inlet Temperatures in Hydrodynamic Bearings" from Heshmat and Pinkus. ASME J. Tribol. 1986, 108, 231-248.

13. Wasilczuk, M.; Wodtke, M.; Braun, W. Centrally Pivoted Tilting Pad Thrust Bearing with Carbon-Based Coated Collar-Experimental Results of Low-and Medium-Speed Operation. Tribol. Trans. 2015, 58, 882-893. [CrossRef]

14. Wodtke, M.; Wasilczuk, M. Study of the Heat Transfer between Thrust Bearing Pads; Internal Research Project No 020682 for GE; Gdansk University of Technology: Gdansk, Poland, 2014.

(c) 2018 by the authors. Licensee MDPI, Basel, Switzerland. This article is an open access article distributed under the terms and conditions of the Creative Commons Attribution (CC BY) license (http://creativecommons.org/licenses/by/4.0/). 